\title{
Conceptualizing "Race" and Racism in Health Disparities Discourse: A Critical Discourse Analysis
}

\author{
Todd Vanidestine $e^{1, *}$ \\ ${ }^{1}$ Adelphi University, USA \\ *Correspondence: Adelphi University School of Social Work, USA. E-mail: \\ tvanidestine@adelphi.edu
}

Received: March 5, 2018 Accepted: April 7, 2018 Published: May 10, 2018

doi:10.5296/jsr.v9i2.12772ＵRL: https://doi.org/10.5296/jsr.v9i2.12772

\begin{abstract}
Critically analyzing how language and discourse influence health policy agendas to eliminate racial and ethnic health disparities (REHD) supports social work's commitment to address oppression and marginalization. Various institutions construct health policy agendas regarding REHD without explicitly conceptualizing terms such as "race," "racism," "African American/Black," "Latino/a," "Asian," and "White", and their relationship to racialized health outcomes. However, there is limited research examining the inherent ideologies and meaning related to racial concepts, which rely heavily on conveying historical influences through discourse over time. The purpose of the current qualitative study is to explore how policy initiatives to address REHD conceptualized "race" and racism. By employing grounded theory (GT) and critical discourse analysis (CDA), the study examined the discourse underpinning city, state, and national policy agendas to eliminate REHD. The study's findings highlighted how terminology, assigned meanings, and ideology are replicated over time to reproduce a non-critical analysis of "race" and racism. The resulting implications suggest that conceptualizing "race" void of understanding differential racial health outcomes as racism omits the structural, historical, and ethical characteristics of racial concepts. Within health disparities discourse, the meanings assigned to "race" and racism ultimately influence which interventions are identified to address REHD.
\end{abstract}

Keywords: health disparities, race, racism, critical discourse analysis 


\section{Introduction}

A majority of current research regarding REHD focuses on differential health outcomes among racial groups, without defining "race" and racism (Paradies, 2006a,b; Williams \& Mohammed, 2013). Policy agendas that rely heavily on individuals' health behaviors or "lifestyle theory" approaches to addressing inequitable racial and ethnic health outcomes often limit the analyses of systemic factors such as language and discourse (Gamble \& Stone, 2006). People with greater access to resources, media, and state-sanctioned institutions often communicate meaning of racial concepts through language and discourse (Goldberg, 1993). The ability to communicate particular messages via spoken and written words is an important aspect of social power, especially as it relates to policy-making and implementation (Fairclough, 2010). On one hand, conceptualizing "race" and racism as structural and sociopolitical factors could offer a more comprehensive understanding of the root causes of health disparities; conversely, the process could reproduce racial meanings that reinforce an individual-focused understanding of racialized health outcomes and limit policy options (Hofrichter, 2003). In turn, social workers can support a broader contextual understanding of REHD by conceptualizing "race" and racism as institutional- and structural-based ethical concepts (National Association of Social Workers [NASW], 2007; NASW, 2008; Social Work Policy Institute [SWPI], 2014).

The current study examined how "race" and racism are conceptualized within various initiatives to eliminate REHD. To do so, health promotion initiatives related to REHD at the city, state, and national levels using critical discourse analysis (CDA) and grounded theory (GT) were analyzed to examine the racialized meanings of REHD language and discourse. Rather than a traditional literature review, the research focused on historical, transdisciplinary influences of how "race" and racism are conceptualized in current health disparities discourse.

\section{Historical Perspective}

\section{1 "Race" and Racism in Health Disparities Discourse}

Differential racial and ethnic health status and outcomes have existed since the founding of the U.S. when Columbus' arrival created a need for free labor in order to seize and secure resource-rich lands (Byrd \& Clayton, 2000). Columbus captured, and attempted to enslave, Indians from the Caribbean, even as the indigenous people he found were "free with their possessions" and offered "to share with anyone" (Columbus as quoted in Zinn, 1995, p. 3). Because their susceptibility to numerous diseases resulted in an inability to fulfill the work demands, physicians deemed Indians as inferior and led to relying on the physical fortitude of enslaved Africans (Byrd \& Clayton, 2000). Health status often reflected a worker's position within an emerging U.S. racial hierarchy. For example, Higginbotham (1978) discussed how owners were legally required to provide White, Christian "servants" with a nourishing diet, a place to live, and clothing while African "slaves" held no legal rights to health.

Between the sixteenth and eighteenth centuries, "race" became a system to identify, classify, 
and rank human differences. The term "race" evolved from a classification term (e.g., kind, type, variety, stock) to a major (subjective) signification of worth and group differentiation (A. Smedley, 2007). By relying on two justifications, religiosity and the enhancement of civilization through conquest, scientists incorporated social and cultural mores into the production of science (Omi \& Winant, 1994; A. Smedley, 2007). While these justifications served their purpose during this particular period, more scientific/naturalistic notions of "race" soon replaced them to rationalize the belief in a racial hierarchy. The assignment of supposedly innate negative/inferior characteristics to People of Color (PoC) and positive/superior characteristics to White people reinforced the racism underpinning the concept of "race" (Byrd and Clayton, 2000). The term "racism" only began to commonly describe the inequitable relationship between White people and PoC in the 1960s, after its usage during the 1930s to describe the Nazis' tortuous treatment of Jewish people (Fredrickson, 2002). Racism actually created "race" rather than a commonly perceived notion that "race" created racism (A. Smedley \& B. D. Smedley, 2005), a point often minimized in the REHD literature.

A consistent theme in conceptualizing "race" and racism often involved a distinction between its individual and macro level manifestations (e.g., institutional, systemic, structural) by often relying on a biological approach to "race." As early as 1881, Frederick Douglass identified the omnipresent nature of racial prejudice and discrimination as moving from an individualized issue to a societal one, reflecting the frequently contested nature of racial oppression (Doane, 1996). During the time period of the 1896 Plessy v. Ferguson "separate but equal" Supreme Court case, Fredrick L. Hoffman, a statistician in the life insurance industry, made widely accepted statistical claims that Black people were inferior to White people and at greater risk for disease (Kahn, 2013). This reinforced the biological (individual) conceptualization of "race" through the emergence of statistical quantification that provided additional justification for racial categorizations and also reifying racial hereditary differences (Zuberi, 2001). However, W. E. B. Du Bois (1899/1996, 1906) countered these conceptualizations of "race" with research revealing the disparities between Black/African Americans and Whites were consequences of a "social disease" resulting from social/environmental conditions rather than from inherent and inferior racial traits. In other words, DuBois (1906) presciently conceptualized social conditions such as "social organizations...the home, and investigations into occupations, education, religion and morality, crime and political activity" as structural [racism-producing] factors influencing people's health or what is now known as "social determinants of health" (p. 5).

Within the last decade, racism was conceptualized as a social determinant of health (SDH; Jee-Lyn García \& Sharif, M. Z., 2015). The SDH approach emerged from the World Health Organization's (WHO) attempt to address health inequities by expanding the conceptualization of health beyond health care access and treatment to include various aspects of communities such as built environment, education, employment, and housing. Solar and Irwin (2010) developed A Conceptual Framework for Action on the Social Determinants of Health under the auspices of the WHO, which identifies structural determinants of health or "root causes" (e.g., racism, sexism, power distribution, unequal 
income distribution) and intermediary determinants of health (e.g., built environment, housing, education, employment, socioeconomic position). The structural determinants of health "operate at the macro or system level and are embedded in ideology, governance, policies, and institutions," which intimately affect the intermediary determinants of health (Patychuk, 2011, p. 26). Conversely, many research studies conceptualize "race" as a fixed concept disconnected from history, culture, or social context, which is evident by the limited discussion in REHD literature (Lee, 2009; Paradies, 2006b). Minimizing the definitions related to racial concepts can result in treating "race" "as a function of fixed differences between "populations"” or as an inherently biological phenomenon rather than a social construct (James, 2008, p. 42). Racial features are then seen as a causal factor assigned to entire groups of people regarding a multitude of social issues, whereby the individual becomes the focal point for change (Zuberi, 2001). Thus, de-emphasizing the health care, political, and economic systems as causal factors requiring additional attention.

The meaning assigned to any conceptualization of "race" and racism relies heavily on language and discourse, although consensus regarding the "correct" conceptualization is elusive. Choosing, reproducing, and interpreting discourse also represent examples of social power whereby underlying ideologies transmit meaning to society. To better understand how "race" and racism are conceptualized, the current study analyzed discourse from initiatives addressing REHD at the city, state, and national levels. The guiding research question of this study is: How are "race" and racism conceptualized within the health disparities discourse of national, state, and city policy initiatives whose expressed purpose is to address disparate racial and ethnic health outcomes?

\section{Methodology}

The current study employed complementary qualitative methods in the spirit of critical inquiry. Through the use of GT and CDA, the analysis focused on how racial meanings are transmitted through language. GT provided a qualitative coding methodology "to separate, sort, and synthesize" the data, in addition to thematically categorizing its segments (Charmaz, 2006, p. 3). CDA offered another level of investigation as to how dominant social practices, language, texts, and ideologies are constituted and reproduced to perpetuate unequal power relations that result in structural oppression (van Dijk, 1993). CDA interrogated the underlying ways texts are constructed (discourse as text) and produced/interpreted/reproduced (discourse as practice) while also revealing the ideological/social power elements inherent within texts (discourse as social practice). Discourse can refer to written and spoken language; to a specific type of language usage in a particular social situation (e.g., racial discourse, social work discourse, clinical discourse); or "to different ways of structuring areas of knowledge and social practice" (e.g., biomedical discourse, social determinants of health discourse; Fairclough, 1992, p. 3). Combining the coding process of GT with CDA offered complementary methodologies to explore the racial discourse employed within the initiatives to address REHD at the city, state, and national levels. Throughout the analysis, I allowed the heterogeneity of data to reveal itself without 
attempting to fit it into a methodological "box" or a homogenous, singular "reality" (Padgett, 2008). It supported a methodological approach to determine what the text represented rather than forcing the discourse into preconceived themes.

\subsection{Data Collection}

Although data collection and analysis are presented as distinct sections for organizational purposes, GT and CDA allowed for concurrent text analyses as soon as they were collected. The included texts focused on initiatives to eliminate or reduce racial and ethnic health disparities at the city, state, and national levels. The following four documents were included in the analyses: a) Healthy Baltimore 2015 (city); b) Maryland Plan to Eliminate Minority Health Disparities 2006-2010 and 2010-2014 (state); and c) Department of Health and Human Services (HHS) Action Plan to Reduce Racial and Ethnic Health Disparities (2011; national). All of these documents were publicly available through the Internet. Each of the identified texts was initially reviewed to ensure that they related to reducing or eliminating REHD.

Healthy Baltimore 2015 (Healthy Baltimore plan) is framed as a "comprehensive health policy agenda" that identifies specific prioritized health indicators in an effort to reduce "morbidity and mortality and improve the quality of life for City residents" (Spencer, Petteway, Bacetti, \& Barbot, 2011, p. 4). The explicit purpose is to identify challenges and priorities in order to use "the goals and indicators provided in the report to go beyond traditional health measures and explore the root causes that tend to drive health inequities" ( $\mathrm{p}$. 3). The Maryland Plan to Eliminate Minority Health Disparities (MD Plan) comprised two texts: one for planning (2006-2010; Maryland Department of Health and Mental Health [DHMH], 2006) and the other for implementation (2010-2014; DHMH, 2010) to examine the causes, solutions, and potential barriers to addressing "minority" health disparities. The purpose of the plan "is to provide information to assist Maryland's communities in planning and implementing ways to reduce minority health disparities" (DHMH, 2006, p. 14). The Department of Health and Human Services' (HHS) 2011 Action Plan to Reduce Racial and Ethnic Health Disparities (HHS Plan) represents a comprehensive federal-level plan to "reduce" racial and ethnic health disparities, which builds upon other national strategies to improve health such as the Affordable Care Act of 2010 (Koh, Graham, \& Glied, 2011). The vision of the HHS Action Plan is "a nation free of disparities in health and health care" ( $p$. 11).

\subsection{Data Analysis}

The GT coding strategy for each document included initial coding, focused coding, axial coding, and thematic identification (Charmaz, 2006). A thorough manual coding process was conducted by electronically annotating each text using the commenting and highlighting functions in the Apple Preview Application. GT provided a preliminary view of codes, categories, themes, and emerging discourses in the written texts, which served to reveal the "surface-level" meaning of the data, identify possible gaps in the data, and allowed for comparisons among the data (Charmaz, 2006). Although a traditional GT analysis would include identifying a theory, the current study only employed grounded theory's coding 
strategies to complement the discourse analysis.

After using GT to categorize the data by themes, I used CDA to evaluate the various aspects of discourse and their relationship to producing meaning, a form of power (van Dijk, 1993). Fairclough's (1992) approach to CDA follows a three-dimensional theoretical foundation (social theory of discourse) by framing discourse as text, practice, and social practice, in addition to analyzing their interconnectivity. The text analysis (discourse as text) focused on examining related racial concepts through term frequency counts, inclusion/exclusion of particular terms, and related definitions. Language forms the basis of texts; it socially shapes (constitutes) social identities, social relations, and systems of knowledge and beliefs (Fairclough, 1992). Subsequently, the way texts are written reflect the discursive and social practices found in society-at-large.

Theoretically, Fairclough (1992) emphasizes the complementary relationship between the text dimension and the discourse as practice dimension. Discourse as a practice "involves processes of text production, distribution, and consumption, and the nature of these processes varies between types of discourse according to social factors," whereby the context of these processes can shift the eventual text product (Fairclough, 1992, p. 78). "Traces" of the production process and "cues" for the interpretation process form the basis of intertextuality, which refers to the explicit or implicit transposing/merging of portions (quotations, using specific phrases) of preceding text(s) into creating additional text(s), which establishes important historical and ideological linkages among them (Fairclough, 1992). Identifying the interrelatedness of discursive meaning is critical because it relates to text creation and establishing connections to the third dimension, social practice.

Discourse as social practice indicates fluid movement between the perspectives of social structure and social action/agency (Fairclough, 1992). Discourse operates broadly within social practices in several ways: (a) through the production of cultural, political, and economic aspects of social life; (b) through individual discursive practices manifest within a network, and in relationship with, other practices "where these 'external' relationships determine its 'internal' constitution," a recontextualization of discourse; and (c) through reflexive discursive practices, as "people always generate representations of what they do as part of what they do," by creating identities such as race, gender, and class (Chouliaraki \& Fairclough, 1999, p. 22). Ideologies are (re)produced and conceptualized through language as meaning, which leads to knowledge production through language, so that discourse is not only a linguistic phenomenon but also a social practice (Fairclough, 1992). Ideologies can then reproduce imbalances of power and domination through hegemonic ideas, leading to what can become "common sense" values representing dominant classes' mores (Fairclough, 2001; Stoddart, 2007). The next section discusses results from the GT and the CDA analyses.

\section{Findings}

\subsection{Grounded Theory}

The primary purpose of each text focused on plans and actions to address REHD. However, 
there was limited explanation or discussion regarding race-specific concepts such as racial categories, racial terms, or the historical, political, and economic aspects of inequitable racial health outcomes within the documents. In addition to examining explicit references to racial concepts, I also examined what interventions were emphasized to better understand the conceptualization of "race" and racism. According to Stone (2012), how we define a social issue leads to particular solutions assuming the solution corresponds to how a social issue is defined.

The GT analysis highlighted the general themes of each document in order to familiarize the researcher with the texts' content, which segued into the CDA. All three policy initiatives included the following four GT themes: a) health promotion and access to health care; b) engagement and collaboration; c) data collection and monitoring; and d) policy and legislation actions. The Maryland Plan and the HHS Plan shared two additional themes-diversifying the workforce and cultural/linguistic competency. The Maryland Plan was the only document to explicitly define "race" and ethnicity, while all the initiatives did not explicitly frame differential health outcomes as racism or as consequences of racism. It is important to highlight how the themes focused on actions taken to address REHD rather than specifically defining or conceptualizing "race" and racism, which will be further discussed in the CDA section, "Discourse as Social Practice," below. The following CDA employed Fairclough's (1992) three-dimensional analysis of discourse as text, as practice, and as social practice.

\subsection{Critical Discourse Analysis}

\subsubsection{Text Analysis}

The text analysis focused on frequency counts of race- and health-related language. CDA highlighted the exclusion/inclusion aspect of discourse where suppression of particular words, concepts, actors, and discourses reveal as much about a social issue as what is actually included (Fairclough, 2003). In other words, "what is 'said' in a text is 'said' against a background of what is 'unsaid', but taken as a given" (Fairclough, 2003, p. 40). The following concepts and terms were included in the frequency count: a) minority/minorities; b) race; c) racism; d) White/Whiteness; e) disparity/disparities; and f) inequity/inequities. The term or concept was only counted if it appeared within the body of the policy. Table 1 below indicates the frequencies of terms from each policy agenda. Each initiative at the city, state, and national level generally preferred the use of "race" and "White," rather than "racism" or "Whiteness," respectively.

Omitting "race" or providing limited context of the concept, as it relates to health, is a common phenomenon across research addressing racialized health outcomes (Paradies, 2006a, 2006b). The Maryland Plan defined "race" as "an inexact socio-biological category, but commonly accepted....", which contains conflicting messages (Maryland Department of Health and Mental Health, 2006, p. 18). By adding the phrase "commonly accepted," the definition presented the sociological and biological perspectives as equally accepted generally, and specifically in relationship to racial health disparities. Similarly, the HHS Plan (2011) also equated the credibility of both biological and social constructivist factors by stating that 
“...[racial and ethnic] health disparities arise from biologic factors and social factors that affect individuals across their lifespan” (p. 2). By including the biological perspective, a more individualized meaning of "race" is conveyed rather than an institutional or systemic understanding (Gómez, 2013). A biological definition of "race" also leads to racializing bodies of color as inherently "defective, weak, or diseased," which replicates a historically dominant racial discourse relegating PoC an inferior position in society (Kahn, 2013, p. 26). Both the individualized and racialized meanings inherent to the biological meaning of "race" can lead to understanding inequitable health outcomes as attributable to the individual's innately inferior characteristics instead of structural forces within society. Doing so is all the more problematic when considering the extensive literature indicating the specious nature of "race," which often veils the reality of racism (American Anthropological Association, 1998; NASW, 2007; A. Smedley \& B. Smedley, 2005).

Table 1. Concept Frequencies-Policy Initiatives

\begin{tabular}{cccc}
\hline Concepts & $\begin{array}{c}\text { Healthy } \\
\text { Baltimore }\end{array}$ & $\begin{array}{c}\text { MD Plan } \\
\text { 2006-2010/ } \\
2010-2014\end{array}$ & HHS Plan \\
\hline Minority/minorities & $0 / 0$ & $268 / 70$ & $37 / 29$ \\
Race & 22 & 91 & 13 \\
Racism & 0 & 0 & 0 \\
White/whiteness & $15 / 0$ & $123 / 0$ & $12 / 0$ \\
Inequity/inequities & $0 / 7$ & $2 / 3$ & $0 / 0$ \\
Disparity/disparities & $3 / 1$ & $80 / 421$ & $12 / 127$ \\
\hline
\end{tabular}

The prevalent conceptualization of "race" across all initiatives involved racially categorizing people within health disparities data. Racial categories are a product of the U.S Office of Management and Budget [OMB] (1997) Statistical Directive 15 (Standards for Maintaining, Collecting, and Presenting Federal Data on Race and Ethnicity). Originally codified in 1977, and updated in 1997, Statistical Directive 15 guides all federal agencies in racial classification (White House, n.d.). Statistical Directive 15 identifies two ethnicities (Hispanic or Latino and Not Hispanic or Not Latino) and five racial categories: a) Black or African American; b) White; c) Asian; d) American Indian or Alaska Native; and e) Native Hawaiian or Other Pacific Islander (OMB, 1997). Such categorizations are often associated with inferior (PoC) and superior (White people) characteristics, which represent a conveyance of meaning across history and further supports the U.S. racial hierarchy in society.

"Race" and "ethnicity" were often used interchangeably and without clearly indicating the malleable nature of each concept. Healthy Baltimore omitted any discussion regarding "race" or "ethnicity" other than as categorizing labels for racial and ethnic groups. The HHS Plan referenced the OMB "minimum standard categories" for racial and ethnic groups, indicating more standardization for "... adequately collecting, reporting, and tracking data on health disparities" was required (p. 5). The Maryland Plan also specifically distinguished between 
"race" and "ethnicity" by relying on OMB Directive 15 categories. However, confusion can arise by attempting to "standardize" and distinguish between the two amorphous concepts. For example, the Maryland Plan attempted to distinguish "ethnicity" and "race" by stating, "“ethnicity" is used to describe groups with a common cultural or language heritage but can, as in the case of Hispanics and Asians, mask significant differences by country or culture of origin" and "race" as "an inexact socio-biological category, but commonly accepted...." (Maryland Department of Health and Mental Health, 2006, p. 18). Conflating "Hispanics" and "Asians" as ethnic groups contradicted Directive 15 designating "Asians" as a racial group, which created an additional barrier to a clear conceptualization of "race."

All the texts used racial categories within a "comparative framework" to establish interventions and to analyze progress toward eliminating disparities by comparing health outcomes among racial and ethnic groups. Such racial comparative approaches are shown to limit the identification of factors causing health disparities, the possible interventions, and overemphasize the perceived common characteristics within each racial group (Bediako \& Griffith, 2007). Concurrently, racial health disparities' initiatives often conflate "disparity reduction with minority health promotion" and "impedes the ability to precisely conceptualize, define, and measure target goals" [emphasis in original] (Bediako \& Griffith, 2007, p. 53). In the U.S. context, health promotion efforts can narrowly focus on individual lifestyle behaviors (e.g. eating better food, exercising more, etc.; see Gamble \& Stone, 2006). Minimizing structural determinants of health such as racism further emphasized the individuals' responsibility (Solar \& Irwin, 2010). Combining the biological meaning of race with a health promotion approach to REHD resulted in an individualistic presentation of "race."

\subsubsection{Discourse as Practice Analysis}

Discourse as practice connects the features of text dimension to discourse as a social practice dimension of Fairclough's (1992) approach to CDA, whereby the language of texts is reproduced and interpreted leading to a conveyance/convergence of meanings between text creator(s) and text consumer(s). Specifically, analyzing discourse practice examines how cues or meanings from earlier texts are found in subsequent written or spoken words and each text is an amalgamation of messages based on the writer's or speaker's influences (Fairclough, 1992). Concurrently, the intended meaning produced by the text creator intersects with the text consumer's pre-established conceptual understanding. For example, scholars presenting "race" as an ahistorical, unchangeable concept will either fit into the reader's understanding or not, whereby "race" could easily become disconnected from its manifestation as racism and replicate a non-critical conceptualization of race.

Differential health outcomes among racial and ethnic groups formed the basis for conceptualizing "race," without an explicit reference to racism as a contributing factor or identifying the outcomes as examples of racism. The Maryland Plan defined "minority" health disparities, "as differences in the incidence, mortality, and burden of diseases and other adverse health conditions among the historic [sic] disenfranchised minority groups [non-White racial groups] in the state" (p. 11). Similarly, the HHS Plan defined "race" as a 
category within "health disparities” by stating, “...persistent and well-documented health disparities exist between different racial and ethnic populations and health equity remains elusive. Health disparities - differences in health outcomes that are closely linked with social, economic, and environmental disadvantage..." [emphasis added] (p. 1). The use of "[racial] disparities" (as the social issue) in direct relationship with "health equity" (as the solution) illustrates conceptual incongruity. Logic dictates that if "equity" is the goal then "inequity" (not "disparity") is the social issue. Whitehead (1992) clearly distinguished "inequity" and "disparity" where the former relates to injustice, unfairness, and avoidability rather than neutral differences as reflected in the latter term.

Key theoretical and analytical components of discursive practice include transmitting ideological meanings across texts, or intertextuality, and between micro- and macro-levels of society (Fairclough, 1992). Intertextuality is most commonly found in the form of "reported speech" (including writing and thought), where attribution of a previous text's influence may or may not exist (Fairclough, 2003, p. 219). Reported speech usually manifests as "direct reporting" (quotations or using the same terminology) or as "indirect reporting" (summarized version of content, not the actual words). Analyzing the transmission of meaning across time periods and texts reflects how various types of knowledge are prioritized or marginalized. This is evident across federally sanctioned attempts to reduce or eliminate REHD.

The 1985 Report of the Secretary's Task Force on Black and Minority Health (Heckler Report) first identified differential health outcomes among racial groups ("racial and ethnic health disparities") as a government-recognized social issue (Stone, 2006). Over the last 30 plus years, REHD became much more prominent due in large part to the Institute of Medicine's groundbreaking study, Unequal Treatment: Confronting Racial and Ethnic Disparities in Health Care (Unequal Treatment Report; B. D. Smedley, Stith, \& Nelson, 2003). The study increased public awareness and visibility of REHD, which led to "general system and cross-cultural education interventions to reduce [them]" (Chin, Walters, Cook, \& Huang, 2013, p. 761). Table 2 identifies common approaches to addressing REHD found across the Heckler Report, Unequal Treatment Report, and common themes from the U.S. initiatives in this study. The common interventions for REHD are readily apparent through direct and indirect reporting across the last 30 years. All three initiatives made limited or no reference to the Heckler Report yet presented very similar strategies to address REHD. This exemplified how meaning is assigned to a social issue through the actions assigned to address it. Except for the theme "policy and legislative actions," the remaining themes represented non-systemic approaches to addressing REHD. Thus, the meanings associated with the actions also impart meaning to "race" and its connection to differential (not explicitly deemed as unjust or unfair) health outcomes. Although the Maryland Plan was the only one to explicitly mention the Heckler Report, the shared language and meaning across all the initiatives and the 30-year time span is apparent. When discussed, "race" and racism are often implicitly associated with the themes of cultural competency and diversifying the workforce (diversity), which are often disconnected from social justice and explicit discussions about racism in relationship to REHD (Kumagai \& Lypson, 2009).

Without explicit reference to racial concepts, the analysis turned to the hidden racial 
discourse describing people suffering the consequences of REHD. Conceptualizing "race" through non-racial terms such as "minority" offered an example of direct reporting. The Maryland Plan directly quoted a definition of "minority" from the 2004 Maryland Health Care Disparities Initiative, included in House Bill 86, "In this Plan, minority is defined as members of the following groups: African American, American Indian, Hispanic, and Asian/Pacific Islander. This definition of minority groups is based on House Bill 86, from the 2004 Maryland Legislative session" (DHMH, 2006, p. 18). Although no quotations marks were included, an intertextual chain emerged connecting a racialized identifier ("minority") across state-level legislation and initiatives to address racial health disparities without further contextualizing structural and historical racial meanings (Fairclough, 1992).

Table 2. Historical Comparisons of Racial Health Disparities' Interventions

\begin{tabular}{|c|c|c|}
\hline $\begin{array}{c}\text { Heckler Report } \\
\text { (1985) }\end{array}$ & $\begin{array}{c}\text { Unequal Treatment } \\
\text { (2003) }\end{array}$ & $\begin{array}{l}\text { U.S. Initiatives } \\
\text { (City, State, \& National) } \\
\text { Themes; 2006-2011) }\end{array}$ \\
\hline $\begin{array}{l}\text { Health information and } \\
\text { education }\end{array}$ & $\begin{array}{l}\text { Patient education \& } \\
\text { empowerment }\end{array}$ & Health promotion \\
\hline $\begin{array}{l}\text { Delivering and financing } \\
\text { health services }\end{array}$ & $\begin{array}{l}\text { Health systems } \\
\text { interventions }\end{array}$ & Access to healthcare \\
\hline Data development & $\begin{array}{l}\text { Data collection \& } \\
\text { monitoring }\end{array}$ & Data collection \\
\hline Research agenda & Research needs & Data monitoring \\
\hline $\begin{array}{l}\text { Health professionals' } \\
\text { development }\end{array}$ & $\begin{array}{l}\text { Cross-cultural education in } \\
\text { the health professions }\end{array}$ & $\begin{array}{l}\text { Cultural and linguistic } \\
\text { competency }\end{array}$ \\
\hline $\begin{array}{l}\text { Cooperative efforts with } \\
\text { non-Federal sector }\end{array}$ & $\begin{array}{l}\text { Legal, regulatory, \& policy } \\
\text { interventions }\end{array}$ & Engagement and collaboration \\
\hline N/A & $\begin{array}{l}\text { Legal, regulatory, \& policy } \\
\text { interventions }\end{array}$ & Policy and legislative actions \\
\hline N/A & N/A & Diversifying the workforce \\
\hline
\end{tabular}

The Maryland Plan and HHS Plan represented PoC as "minority/minorities," which implicitly reinforced a subordinated position of relative economic and social power for racial and ethnic groups of color in relationship to their White counterparts. For example, the common understanding of "minority" often refers to a group that consists of numerically fewer people 
than a majority. However, problems arise in cities like Washington, D.C., Baltimore, MD or El Paso, TX where the numerical majorities are African Americans or Latinas/os, yet they are still referred to as "minorities." Although PoC may be in the majority numerically, they are still referred to as "minorities" or "majority minority," which reflects a relationship to power rather than solely a numerical concept. If "minority" only meant fewer numerically in relation to the majority, there would be no need for the term "majority minority" (see The Washington Post [May, 17, 2012] front page headline, "Minority babies majority in U.S."). Consequently, terms such as "minority" reinforce the U.S. racial hierarchy through its repetition in research, education across multiple professions, and policies including state and federal "Office(s) of Minority Health." Differentiating "minority" groups across health outcomes data emphasized a racial discourse of difference, which contributed to a color-blind racial ideology. The next section will focus on the discourse of differences as a social practice, where "race" and racism were conceptualized within prescribed interventions and actions to address REHD.

\subsubsection{Discourse as Social Practice}

Discourse practices are contextualized within, and as, broader social practices, where people are creating/(re)producing/interpreting texts. Social practices operate as control mechanisms regarding the inclusion "of certain structural possibilities and the exclusion of others" over time whereby "orders of discourse" related to racial health disparities represent "socially structured" choices across numerous linguistic possibilities (Fairclough, 2003, p. 23). The hierarchical aspect of various discourses (differences vs. injustices, cultural competency vs. anti-racism practice) demonstrates how power is manifested through ideological aspects of language (Fairclough, 2001). In other words, the discussion regarding "race" or racism in health disparities discourse often relies on non-explicit racial conceptualizations, employing color-blind (non-racial) language to reveal the ideological meanings of racial concepts (Bonilla-Silva, 2010).

Racial categorization and labeling among different groups of people, without incorporating a structural analysis of racism, reinforced the process of racialization. By defining, interpreting, formulating, and assigning racial meanings that underpin racialization, the dominant racial group has the cultural, political, and social power to replicate this process across multiple levels of society, intentionally or not (Bonilla-Silva, 1997). Assigning and ascribing racial differences often levy judgments upon the racialized "other" (Fassin, 2011). The process of racialization usually includes a combination of assigning individual physical characteristics, such as hair, body types, and facial features, a value-based social meaning. These characteristics are then assigned to cultural aspects of an entire racial group to establish their relative position in a racial hierarchy (A. Smedley, 2007). In turn, these become racialized descriptors serving to reify racial categorizations and their associated cultural messages, leading to a "common sense," uncritical understanding of taken-for-granted racial concepts (Teo, 2000). These racialized messages conveyed via "differences" between racial groups' health outcomes form the basis for how we, as a society, take action to solve them. "Racial health differences" then become reified as the social issue, and concurrently minimizing the unjust or unethical aspects of these outcomes. Therefore, the proposed interventions and framing of racialized health outcomes reinforced a narrowly conceptualized understanding of 
"race."

Focusing on racial health differences and labeling racial groups as an ethically neutral process also obscures the "how" of their emergence from socially constructed binary positions, where "White" represents the "good," "norm," and ultimately the standard by which all other non-White groups are construed as "different" (Dyer, 1997). What appeared as a benign conceptualization of "race" actually represented an inherently political and "ideological" replication of racial classifications/groupings as "less evaluative and more factual generalizations" leading to their acceptance as "...less questionable and more naturalized" (Teo, 2000, p. 17). "Genomic science" has now created a new acceptability for the explicit use of racial differences as they relate to health (Roberts, 2011). The color-blind approach to "race" (a racial ideology) is inherently supportive of "the new racial science based on genetics," where commentators conceptualize "genetic race" as a "scientific truth" and "social race" as a "politically correct ideology" (Roberts, 2011, pp. 291-292). Bonilla-Silva (2010) frames this color-blindness as a form of "color-blind racism," which represents the maintenance of racial order with facially non-racial language and practices. Thus, racial ideology can operate dichotomously as both an explanatory rationalization for the prevailing racial hierarchy and oftentimes de-emphasizes systems' (health, social welfare, political, legal etc.) culpability. The resulting discourse of color-blind, differential health outcomes and interventions replicated the power to define both the issue and people affected, thus reproducing a de-contextualized understanding of "race" and racism.

Presenting complex concepts such as "race" and racism without a clear definition contextualizing its meaning allows apolitical and ahistorical conceptualizations to continue. For example, the use of "White" as a reference racial group and identity in the initiatives without understanding its social ramifications also served to support an apolitical, non-structural analysis of factors influencing racialized health outcomes. Consequently, "White" racial identity was included as a narrowly defined racial identity in each of the texts. Conversely, the complimentary term "Whiteness" (as a critical race concept) was omitted. Thus the "differences" between racial groups relied heavily on social identities, in this case "race," rather than differences in conferred privileges and social power through political, legal, and economic processes as compared to the dominant racial group (Harris, 1993; López, 2006). The underlying privileging and racializing processes within those systems' policy texts can reinforce the U.S. racial hierarchy by reifying White racial identity without critically analyzing the structural factors of Whiteness. This racial ordering is sometimes referred to as a "form [conceptualization]" of racism vis-à-vis "the institutional and cultural practices through which Whites strive to maintain their hegemonic position" (Doane, 2006, p. 258). By omitting a structural analysis of "racism" and "Whiteness" within the discourse of racialized health outcomes, the initiatives minimized contributing structural factors and implicitly emphasized the individual's responsibility for the issue.

\section{Discussion and Conclusion}

The current study examined how "race" and racism were conceptualized within racial and 
ethnic health disparities discourse within city, state, and national initiatives to address REHD. Collectively, the policy initiatives focused on focused on two complementary discourses, racial categorizations and racial differences across health outcomes, as the basis for predominantly individual-focused interventions. The ideology embedded within these racial discourses regarding health disparities reflects "a refusal to recognize its systemic origins, roots, or logic, and therefore attempts to explore the relationship of political power to health inequities appear fruitless" (Hofrichter, 2003, pp. 26-27). The limited recognition of a systemic influence of "race" and racism is evident in the current findings, which previous studies also reflect. In an extensive systematic review, Paradies (2006b) examined 138 studies that included participant exposure to racism as it related to a health outcome. Only 34 of the total studies included a definition of racism and even fewer (17) conceptualized racism as "systemic," referring to racism emanating from processes within organizational, institutional, legal, or policy-related settings. Similarly, Lee (2009) examined the use of "race" and ethnicity in 166 biomedical research studies. Only 39 defined "race" or ethnicity and a vast majority (35) defined these concepts as "self-defined," referring to participants" understanding of the concepts. Both studies, in conjunction with the current research, highlight the lack of emphasis on systemic factors influencing unjust racial health outcomes and how this then reinforces an unclear definition of racial concepts.

Similar to other helping professions and academic fields of study, social work struggles with contested discursive and ideological approaches to "race" and racism. Consequently, the majority of social work education, research, policy and practice conceptualizes "race" and racism through the complementary prisms of cultural competence and diversity. Several social work scholars have challenged the efficacy of cultural competence because of its "equality-of-oppression" approach that minimizes the impact of racism (Schiele, 2007, p. 83), its "apolitical or de-political nature" (Sakamoto, 2007, p. 108), or because it does not reach "far enough in addressing systemic and institutionalized oppressions" (Abrams \& Moio, 2009, p. 247). The current study's findings represent ideological manifestations of racial meanings that further presents inequitable racial health outcomes as an individual-/interpersonal-based issue rather than a systemic-/structural-based phenomenon.

Given the prominence of racial categorization and racial differences as influential meanings associated with "race" and racism in the REHD initiatives, a racial ideology emerged from the study's findings. By not defining "race" and racism or defining "race" as an exclusively descriptive/categorical factor to represent racial differences, the initiatives presented a collectivized (mis)understanding about racial health disparities based on "race" as neutral, a political concept removed from producing unjust health outcomes. Bonilla-Silva (2010) refers to this as a "race without racism" approach to differential health outcomes, which ironically leads to a "color-blind racism" ideology whereby not explicitly identifying (colorblind) racism as an outcome of "race" perpetuates a form of racism. In other words, when racial concepts are operationalized within practice, research, or education solely as a way to categorize groups based on racial differences, racial ideology operates as both an explanatory rationalization for the prevailing racial hierarchy and a point of resistance for subordinate racial and ethnic groups (Bonilla-Silva, 2010). Within these ideological 
significations lies inherent power to frame racial health outcomes as "differences" rather than considering them as racial "injustices" (racism), which can further conceal ethical and systemic factors while implicitly suggesting a narrow, individualized view of REHD. Johnstone and Kanitsaki (2010) emphasized the moral obligation to address racism in healthcare as an ethical issue, which requires a comprehensive understanding of racism and how that understanding intersects with professional ethical values to make systemic changes. Interventions focused on addressing racial "differences" in health outcomes often reflected the non-systemic meanings of "race" and racism in health disparities discourse, which was clearly indicated by Bailey, Krieger, Agénor, Graves, Linos, and Bassett, (2017) when the researchers found only 195 articles (out of 47,855 articles) referenced "structural" or "systemic" racism when "race" was searched in conjunction with "health", "disease", "medicine", or "public health".

According to the NASW Code of Ethics (2008), social workers are ethically bound to address REHD. Additionally, the profession has emphasized specific actions to address systemic and structural racism. Such ethic and justice focused considerations require a critical approach to analyzing racial concepts in health disparities discourse. By doing so, systems and institutions are framed as possible barriers to equitable health outcomes, rather than benevolent entities assumed to support solutions. As professionals with access and influence to these institutions, social workers can employ more critical approaches to REHD such as critical race theory (CRT; Constance-Huggins, 2012), anti-racist health care practice (McGibbon \& Etowa, 2009), structural determinants of health (Solar \& Irwin, 2010), and web of institutional racism (Miller \& Garran, 2007). These approaches place an emphasis on conceptualizing "race" and racism as systemic, historical and political influences related to social power, thus broadening the scope of interventions and their efficacy.

Policy creation and its connection to historical and political influences are vital components of the conceptualization of unjust racial health outcomes. As the findings highlighted, the U.S. policy texts focused on apolitical, race-neutral interventions to address health differences between races. Further research on how social welfare and health professionals actually implement interventions based on this conceptualization of "race" and racism would add important knowledge to translating racial discursive meanings to actual corrective action. A critical approach to the analysis of racial health inequities discourse frames systems (e.g., governmental, health care, social welfare, legal) as possible barriers to equitable health outcomes, rather than benevolent entities whose every action is assumed to support a solution. As professionals with access and influence within these systems, we can strengthen efforts that emphasize necessary systemic changes and connect them to our professional interactions with community residents.

\section{Acknowledgement}

The research received funding from the University of Maryland, Baltimore School of Social Work PhD Program, with special thanks to Dr. Donna Harrington. I would like to also acknowledge Dr. Michael Reisch (dissertation chair) for his guidance throughout the research 
process, in addition to my entire dissertation committee (Drs. Edward Pecukonis, Megan Meyer, Tanya Sharpe, and Susana Martinez-Guillem).

\section{References}

Abrams, L. S., \& Moio, J. A. (2009). Critical race theory and the cultural competence dilemma in social work education. Journal of Social Work Education, 45(2), 245-261. https://dx.doi.org/10.5175/JSWE.2009.200700109

American Anthropological Association. (1998). American Anthropological Association statement "race." Retrieved from http://www.americananthro.org/ConnectWithAAA/Content.aspx?ItemNumber=2583

Bailey, Z. D., Krieger, N., Agénor, M., Graves, J., Linos, N., \& Bassett, M. T. (2017). Structural racism and health inequities in the USA: Evidence and interventions. The Lancet, 389, 1453-1463. https://dx.doi.org/10.1016/S0140-6736(17)30569-X

Bediako, S. M., \& Griffith, D. M. (2007). Eliminating racial/ethnic health disparities: Reconsidering comparative approaches. Journal of Health Disparities Research and Practice, 2(1), 49-62. https://digitalscholarship.unlv.edu/jhdrp/vol2/iss 1/5

Bonilla-Silva, E. (1997). Rethinking racism: Toward a structural interpretation. American Sociological Review, 62(3), 465-480. https://dx.doi.org/10.2307/2657316

Bonilla-Silva, E. (2010). Racism without racists: Color-blind racism and racial inequality in contemporary America. Lanham, MD: Rowman \& Littlefield.

Byrd, W. M., \& Clayton, L. A. (2000). An American health dilemma: A medical history of African Americans and the problems of race beginnings to 1900. New York: Routledge.

Charmaz, K. (2006). Constructing grounded theory: A practical guide through qualitative analysis. Thousand Oaks, CA: Sage.

Chin, M. H., Walters, A. E., Cook, S. C., \& Huang, E. S. (2013). Interventions to reduce racial and ethnic health disparities in health care. In T. LaVeist \& L. Isaac (Eds.), Race, ethnicity, and health: A public reader (pp. 761-785). San Francisco, CA: Jossey-Bass.

Chouliaraki, L., \& Fairclough, N. (1999). Discourse in late modernity: Rethinking critical discourse analysis. Edinburgh: Edinburgh University Press.

Constance-Huggins, M. (2012). Critical race theory in social work education: A framework for addressing racial disparities. Critical Social Work, 13(2), 1-16.

Doane, A. (1996). Contested terrain: Negotiating racial understandings in public discourse. Humanity \& Society, 20(4), 32-51. https://dx.doi.org/10.1177/016059769602000404

Doane, A. (2006). What is racism? Racial discourse and racial politics. Critical Sociology, 32(2/3), 255-274. https://dx.doi.org/10.1163/156916306777835303 


\section{1) Macrothink}

Journal of Sociological Research

ISSN 1948-5468

2018, Vol. 9, No. 2

Du Bois, W. E. B. (1899/1996). The Philadelphia negro: A social study. Philadelphia: University of Pennsylvania Press. (Original work published 1899)

Du Bois, W. E. B. (1906). The health and physique of the Negro American. Atlanta, GA: Atlanta University Press.

Dyer, R. (1997). White. New York: Routledge.

Fairclough, N. (1992). Discourse and social change. Malden, MA: Polity Press.

Fairclough, N. (2001). Language and power ( $2^{\text {nd }}$ ed.). London: Pearson Education.

Fairclough, N. (2003). Analysing discourse: Textual analysis for social research. New York: Routledge.

Fassin, D. (2011). Racialization: How to do races with bodies. In F. Mascia-Lee (Ed.), A companion to anthropology of the body and embodiment (pp. 419-434). Oxford, United Kingdom: Wiley-Blackwell.

Gamble, V. N., \& Stone, D. (2006). U.S. policy on health inequities: The interplay of politics and research. Journal of Health Politics, Policy and Law, 31(1), 93-126. https://dx.doi.org/10.1215/03616878-31-1-93

Goldberg, D. T. (1993). Racist culture: Philosophy and the politics of meaning. Malden, MA: Blackwell.

Gómez, L. E. (2013). Introduction: Taking the social construction of race seriously in health disparities research. In L. Gómez \& N. López (eds.), Mapping "race”: Critical approaches to health disparities research (pp. 1-22). New Brunswick, NJ: Rutgers University Press.

H.B. 86, Maryland Office of Minority Health and Health Disparities, 2004 Leg., Reg. Sess. (Md. 2004).

Harris, C. I. (1993). Whiteness as property. Harvard Law Review, 106, 1707-1791. https://dx.doi.org/10.2307/1341787

Heckler, M. M. (1985). Report of the Secretary's Task Force on Black \& Minority Health. Washington, DC: U.S. Department of Health and Human Services.

Higginbotham, A. L., Jr. (1978). In the matter of color: Race and the American legal processes: The colonial period. Oxford, United Kingdom: Oxford University Press.

Hofrichter, R. (2003). The politics of health inequities: Contested terrain. In R. Hofrichter (Ed.), Health and social justice: Politics, ideology, and inequity in the distribution of disease (pp. 1-56). San Francisco, CA: Wiley.

James, A. (2008). Making sense of race and racial classification. In T. Zuberi \& E. Bonilla-Silva (Eds.), White logic, white methods: Racism and methodology (pp. 31-45). Lanham, MD: Rowman \& Littlefield Publishers, Inc. 
Jee-Lyn García, J., \& Sharif, M. Z. (2015). Black Lives Matter: A commentary on racism and public health. American Journal of Public Health, 105(8), e27-e30. https://dx.doi.org/10.2105/AJPH.2015.302706

Johnstone, M., \& Kanitsaki, O. (2010). The neglect of racism as an ethical issue in health care. Journal of Immigrant and Minority Health, 12, 489-495. https://dx.doi.org/10.1007/s10903-008-9210-y

Kahn, J. (2013). The politics of framing health disparities. In L. Gómez \& N. López (eds.), Mapping "race": Critical approaches to health disparities research (pp. 25-38). New Brunswick, NJ: Rutgers University Press.

Koh, H. K., Graham, G., \& Glied, S. A. (2011). Reducing racial and ethnic disparities: The Action Plan from the Department of Health and Human Services. Health Affairs, 30(10), 1822-1829. https://dx.doi.org/10.1377/hlthaff.2011.0673

Kumagai, A. K., \& Lypson, M. L. (2009). Beyond cultural competence: Critical consciousness, social justice, and multicultural education. Academic Medicine, 84(6), 782-787. https://dx.doi.org/10.1097/ACM.0b013e3181a42398

Lee, C. (2009). "Race" and "ethnicity" in biomedical research: How do scientists construct and explain differences in health? Social Science and Medicine, 68, 1183-1190. https://dx.doi.org/10.1016/j.socscimed.2008.12.036

López, I. H. (2006). White by law: The legal construction of race. New York: New York University Press.

Maryland Department of Health and Mental Health [DHMH]. (2006). Maryland plan to eliminate minority health disparities: A healthier future for all Marylanders 2006-2010. Retrieved from the University of Pittsburgh, Minority Health \& Health Equity Archive: Retrieved from http://health-equity.pitt.edu/3219/1/MDPlantoEliminateHealthDisparitiesPreliminary200 6.pdf

Maryland Department of Health and Mental Health [DHMH]. (2010). Maryland plan to eliminate minority health disparities: A healthier future for all Marylanders 2010-2014. Retrieved from https://health.maryland.gov/mhhd/Documents/Maryland_Health_Disparities_Plan_of_A ction_6.10.10.pdf

Mautner, G. (2008). Analyzing newspapers, magazines, and other print media. In R. Wodak \& M. Krzyzanowski (Eds.), Qualitative discourse analysis in the social sciences (pp. 30-53). New York: Palgrave MacMillan.

McGibbon, E. A., \& Etowa, J. B. (2009). Anti-racist health care practice. Toronto: Canadian Scholars' Press.

Miller, J., \& Garran, A. M. (2007). The web of institutional racism. Smith College Studies in Social Work, 77(1), 33-67. https://dx.doi.org/10.1300/J497v77n01_03 


\section{Macrothink}

Journal of Sociological Research

ISSN 1948-5468

2018, Vol. 9, No. 2

National Association of Social Workers. (2007). Institutional racism \& the social work profession: A call to action. Retrieved from https://www.socialworkers.org/LinkClick.aspx?fileticket=SWK1aR53FAk\%3D\&portali $\mathrm{d}=0$

National Association of Social Workers. (2008). Code of ethics. Washington, DC: Author.

Office of Management and Budget. (1997). Revisions to the Standards for the Classification of Federal Data on Race and Ethnicity. Retrieved from https://obamawhitehouse.archives.gov/omb/fedreg_1997standards/

Padgett, D. K. (2008). Qualitative methods in social work research. Thousand Oaks, CA: Sage.

Paradies, Y. C. (2006a). Defining, conceptualizing and characterizing racism in health research. Critical Public Health, 16(2), 143-157. https://dx.doi.org/10.1080/09581590600828881

Paradies, Y. C. (2006b). A systematic review of empirical research on self-reported racism and health. International Journal of Epidemiology, 35, 888-901. https://dx.doi.org/10.1093/ije/dyl056

Patychuk, D. (2011). Health equity and racialized groups: A literature review. Health Equity Council and Health Nexus. Retrieved from http://www.healthnexus.ca/projects/building_capacity/index.htm

Roberts, D. (2011). Fatal invention: How science, politics, and big business re-create race in the twenty-first century. New York: New Press.

Sakamoto, I. (2007). An anti-oppressive approach to cultural competence. Canadian Social Work Review, 24(1), 105-114. http://www.jstor.org/stable/41669865

Saperstein, A., Penner, A. M., \& Light, R. (2013). Racial formation in perspective: Connecting individuals, institutions, and power relations. Annual Review of Sociology, 39, 359-378. https://dx.doi.org/10.1146/annurev-soc-071312-145639

Schiele, J. H. (2007). Implications of the equality-of-oppressions paradigm for curriculum content on people of color. Journal of Social Work Education, 43(1), 83-100. https://dx.doi.org/10.5175/JSWE.2007.200400478

Smedley, A. (2007). Race in North America: Origin and evolution of a worldview. Boulder, CO: Westview Press.

Smedley, A., \& Smedley, B. D. (2005). Race as biology is fiction, racism as a social problem is real: Anthropological and historical perspectives on the social construction of race. American Psychologist, 60(1), 16-26. https://dx.doi.org/10.1037/0003-066X.60.1.16

Smedley, B. D., Stith, A. Y., \& Nelson, A. R. (Eds.). (2003). Unequal treatment: Confronting racial and ethnic disparities in health care. Washington, DC: National Academies Press. 
Social Work Policy Institute. (2014). Achieving Racial Equity: Calling the Social Work Profession to Action. Washington, DC: National Association of Social Workers.

Solar, O., \& Irwin, A. A. (2010). A conceptual framework for action on the social determinants of health. Retrieved from http://www.who.int/sdhconference/resources/ConceptualframeworkforactiononSDH_en g.pdf

Spencer, M., Petteway, R., Bacetti, L., \& Barbot, O. (2011). Healthy Baltimore 2015: A city where all residents realize their full health potential. Baltimore, MD: Baltimore City Health Department.

Stoddart, M. C. J. (2007). Ideology, hegemony, discourse: A critical review of theories of knowledge and power. Social Thought and Research, 28, 191-225.

Stone, D. (2006). Reframing the racial disparities issue for state governments. Journal of Health Politics, Policy and Law, 31(1), 127-152. https://dx.doi.org/10.1215/03616878-31-1-127

Stone, D. (2012). Policy paradox: The art of political decision making. New York, NY: W.W. Norton \& Company.

Teo, P. (2000). Racism in the news: A critical discourse analysis of news reporting in two $\begin{array}{lllll}\text { Australian newspapers. Discourse \& } \quad \text { Society, } & \text { 11(1), }\end{array}$ https://dx.doi.org/10.1177/0957926500011001002

U.S. Department of Health and Human Services. (2011). HHS action plan to reduce racial and ethnic health disparities: A nation free of disparities in health and health care. Washington, DC: Author.

van Dijk, T. A. (1993). Principles of critical discourse analysis. Discourse \& Society, 4(2), 249-283. https://dx.doi.org/10.1177/0957926593004002006

White House. (n.d.). Recommendations from the Interagency Committee for Review of the Racial and Ethnic Standards (Federal Register, 7/9/1997, Part II, pp. 36873-36946). Retrieved from https://www.whitehouse.gov/omb/fedreg_directive_15

Whitehead, M. (1992). The concepts and principles of equity and health. International Journal of Health $\quad$ Services, 22(3), 429-445. https://dx.doi.org/10.2190/986L-LHQ6-2VTE-YRRN

Williams, D. R., \& Mohammed, S. A. (2013). Racism and health I: Pathways and scientific evidence. American Behavioral Scientist, 57(8), 1152-1173. https://dx.doi.org/10.1177/0002764213487340

Zinn, H. (1995). A people's history of the United States 1492-present. New York: HarperPerennial.

Zuberi, T. (2001). Thicker than blood: How racial statistics lie. Minneapolis, MN: University of Minnesota Press. 


\section{Copyright Disclaimer}

Copyright for this article is retained by the author(s), with first publication rights granted to the journal.

This is an open-access article distributed under the terms and conditions of the Creative Commons Attribution license (http://creativecommons.org/licenses/by/3.0/). 